Available online on 20.02.2021 at http://jddtonline.info
Oc 2011-21, publisher and licensee JDDT, This is an Open Access article which permits
unrestricted non-commercial use(CC By-NC), provided the original work is properly cited
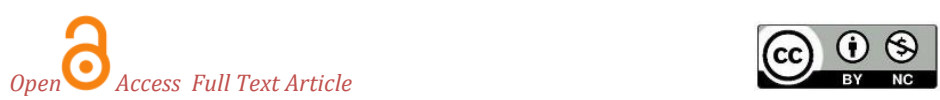

Research Article

\title{
Drug Utilization Evaluation of High Alert Medications in Intensive Care Units of Tertiary Care Teaching Hospital
}

\author{
Meda Venkata Subbaiah"1*, K Leela Prasad Babu², D Manohar³, A Sumalatha ${ }^{3}$, P Mohammed ${ }^{3}$, B Mahitha ${ }^{3}$ \\ ${ }^{1}$ Associate professor in clinical pharmacy, P Rami Reddy Memorial College of Pharmacy, Prakruthi Nagar, Utukur, Kadapa-516003. Andhra \\ Pradesh, India \\ ${ }^{2}$ Assistant professor, Department of General Medicine, Rajiv Institute Of Medical Sciences (RIMS), Kadapa-516003. Andhra Pradesh, India. \\ ${ }^{3}$ Pharm.D Interns of P Rami Reddy Memorial College of Pharmacy, P Rami Reddy Memorial College of Pharmacy, Prakruthi Nagar, utukur, Kadapa- \\ 516003.Andhra Pradesh, India
}

Article Info:

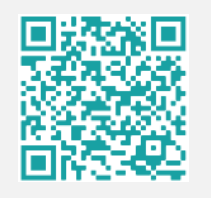

Article History:

Received 11 Dec 2020;

Review Completed 27 Jan 2021

Accepted 09 Feb 2021;

Available online $20 \mathrm{Feb} 2021$

Cite this article as:

Subbaiah MV, Babu KLP, Manohar D, Sumalatha A, Mohammed P, Mahitha B, Drug Utilization

Evaluation of High Alert Medications in Intensive Care Units of Tertiary Care Teaching Hospital,

Journal of Drug Delivery and Therapeutics. 2021; 11(1-s):94-101

DOI:http://dx.doi.org/10.22270/jddt.v11i1-s.4749

\section{Address for Correspondence:}

Meda Venkata subbaiah, Associate professor in clinical pharmacy, P Rami Reddy Memorial College of Pharmacy, Prakruthi Nagar, Utukur, Kadapa516003, Andhra Pradesh, India

\section{Abstract}

Introduction: The utilization of HAMs is crucial in emergency and intensive care departments, as they can cause a significant amount of damage to the patient and health care members if we could not follow the standard treatment guidelines. Drug utilization evaluation/review involves a comprehensive review of the patient's prescription and medication data before, during, and after dispensing to ensure appropriate medication decision making and positive patient outcomes.

Objective: This study was taken up given finding the utilization patterns and rectifying the issues with the usage of high alert medications (HAMs) and improving their utilization.

Methodology: A cross-sectional study was conducted for 6 months at a south Indian tertiary care hospital. Treatment guidelines were prepared to compare the actual drug use. Data were collected both retrospectively and prospectively by patients and care taker's interview, medication chart review, and discussion with prescribers and applied WHO DUE indicators to evaluate utilization patterns.

Results: Of 362 cases, $57.73 \%$ were males/ and the majority geriatrics. Among all HAMs Insulin is frequently prescribed (34.5\%) and the costly drug is Enoxaparin. Generic names were used in writing prescriptions and parenteral formulations were mostly used. Around 9 ADRs were identified and managed, and a total of 133 moderate to severe Drug-Drug Interactions were found, of them, only 2 were actual.

Conclusion: With this study, we conclude that the use of HAMs was found to be appropriate as per the guidelines as we observed very few DRPs with the study drugs.

Keywords: HAM, DRP's, DUE, ICU, DDD

\section{INTRODUCTION}

High-alert medications are drugs that bear a heightened risk of causing significant patient harm while they are used in error. Although mistakes may or may not be more common with these drugs, the consequences of error are more devastating to patients ${ }^{1,2}$. When any medication can potentially cause harm, a select group of drugs "high-alert medications (HAMs)" carries a higher risk of patient injury. According to The Joint Commission (TJC), HAMs frequently are associated with harm, the harm they cause is serious, and when they're misused, the risk of serious injury or death is high $^{3}$.

Based on the previous reports submitted to the ISMP National Medication errors Reporting Program (ISMP MERP), ISMP created an updated list of HAM's ${ }^{4}$. HAM's are commonly used in the emergency room (ER), intensive care unit (ICU), Because HAMs are used in emergencies, they bear a heightened risk of causing patient harm when used incorrectly ${ }^{5}$. Patients who are admitted to ICUs (Intensive Care Unit) are usually seriously ill, often suffer from multiple chronic illnesses and drug usage is also quite extensive. Thus the ICU represents an important platform for performing drug utilization studies. Drug utilization (DU) is defined by the World Health Organization (WHO) as the marketing, distribution, prescription, and use of drugs in society, with special emphasis on the resulting medical, social, and economic consequences 6 . DU involves a wide range of review of the patient's prescription and medication data before, during, and after dispensing to ensure appropriate medication decision making and positive patient outcomes. DU programs play a key role in helping managed health care systems understand, interpret, and improve the prescribing, administration, and use of medications. Drug utilization reviews (DUR) are categorized into three classes: Prospective - evaluation of a patient's treatment before medication is dispensed, Concurrent - ongoing monitoring of drug therapy throughout treatment, Retrospective - review of therapy after the patient has received the medication ${ }^{7}$.

The ultimate purposes of drug utilization studies are to contribute to the optimal quality of drug therapy by 
identifying, documenting, and assessing problems in drug utilization and monitoring the consequences of an intervention?.

Implementing the DUE program in MICU(Medical Intensive Care Unit) and ICCU(Intensive Cardiac Care Unit) helps the health care professionals about the Drug-Related Problems (DRP's) and the changes in the treatment helps to save the newly admitted patients. Until now, the reports related to high alert medications gives information related to prescribing pattern only. Now, we focused to perform Drug Utilization evaluation of High alert medications to minimize the DRP's through which it would be able to stabilize the patient and also minimize health care costs.

This study was aimed to assess the utilization of High Alert Medications in Intensive Care Unit \& Intensive Cardiac Care Unit of the tertiary care teaching hospital with an objective of identifying and rectifying the drug related problems.

\section{METHODOLOGY}

A Cross-sectional study was conducted for 6 months at the Medical Intensive Care Unit \& Intensive Cardiac Care Unit of Government General Hospital - Rajiv Gandhi Institute of Medical Sciences (RIMS), Kadapa.

Daily, patients who were admitted to Intensive Care Units were screened as per eligibility criteria to enroll the subjects in the study. Patients with a minimum of 48 hours of hospital stay in MICU\& ICCU who were prescribed High alert medications/Prescriptions with HAM's and who are willing to give their informed consent to participate are included in the study. Patients who are not having 48 hours of hospital stay, who have prescribed non-high alert medications, Patients receiving high-alert medications at the time of CPR(Cardio-Pulmonary Resuscitation), Patients who are in an unconscious state are excluded from the study. Data from the study subjects were collected by personnel interview, patient's caretaker interview, and medication chart review.
Data includes patient's demographics, past and present medical and medication history, family history, allergies, which were obtained by personnel interview. The clinical review was performed to assess the day-to-day prognosis. Periodically medication trays were examined for the proper labeling of drugs including name and expiry dates, deterioration, damages, misplacements, proper storage, etc. the observed deviations were intimated to the Concerned professionals and rectified. We also monitored the administration process of High-Alert medications the observed deviations were rectified by discussing with the concerned staff. Data was collected, analyzed and the conclusions of the program were intimated to the hospital authorities to bring changes in the utilization of High-Alert medications for the betterment of patient care. We used Descriptive statistics like Mean, SD (Standard Deviation), and Percentage of use of high alert medications by using excel.

\section{RESULTS AND DISCUSSION}

Both retrospective and prospective data of the patients who were prescribed high alert medications were collected for a period of 6 months i.e. from June to November 2019. During the study period, about 1338 cases were reviewed for 6 months, and selected 533 cases/prescriptions containing 23 high alert medications (based on the ISMP list of HAM) ${ }^{8}$ were collected.

Out of 23 drugs, only 7 high alert medications (Atropine, Digoxin, Enoxaparin, Glimepiride, Insulin, Midazolam, Noradrenaline) met the sample size criteria and which accounts for 420 prescriptions in 362 cases and were considered for the in-depth analysis, but for DRPs and interventions, we have considered all 23 drug prescriptions.

\subsection{Patient Demographics:}

The demographic of the patients with gender, age, and social habits and their numeral is represented in Table-1

Table 1: Demographic characteristics of the patients

\begin{tabular}{|l|c|c|}
\hline \multicolumn{1}{|c|}{ Parameter } & No. of Subjects N=362 & Percentage (\%) \\
\hline Gender & 209 & 57.73 \\
Fale & 153 & 42.26 \\
\hline Age & & 0.55 \\
Children (<12) & 02 & 3.31 \\
Teenagers (13 - 19) & 12 & 16.02 \\
Young adults(20 - 39) & 58 & 35.35 \\
Middle-aged adults(40 -59) & 128 & 44.73 \\
Old adults/geriatrics(60-99) & 162 & 8 \\
\hline Social habits & & 4.41 \\
Alcoholics & 29 & 10.49 \\
Smokers & 16 & 2.48 \\
Both alcoholic and smokers & 38 & 74.58 \\
Beetle nut chewers & 9 & \\
Nill & 270 & \\
\hline
\end{tabular}


Of 362 subjects enrolled, $57.73 \%$ were males and $42.26 \%$ were females. We found that the HAMs were prescribed slightly more in males $(57.73 \%)$ than females, in support of our data Manjula Devi et $\mathbf{a l}^{9}$, also reported that prescribing of HAMs is more in males, this represents that, the males are mostly affecting with the life-threatening conditions with more severity and receiving the high alert medications. The incidence of these conditions may be more because of their lifestyles.

We found that the average age of total subjects is $53.40( \pm 17.60)$. We observed that the prescribing of study drugs is more in old adults/ geriatrics i.e. $45 \%$ next to this group $37 \%$ of middle-aged adults have prescribed with these drugs. The results of this study were found to be in coinciding with a previous study conducted by Mitchell Kim et al.,[10] where they reported that the majority of the study subjects with HAM were $\geq 60$ years of age. This may be due to the reason that the age progresses the incidence of highrisk conditions will be increased which was confirmed with these results.

Of 362 subjects, $74.5 \%$ were devoid of social habit. The study results of Mitchell Kim, et. al,10 suggest that the incidence of ICU admissions is more because of the CVS, RS, and CNS disorders associated with social habits. But in contradiction to that study, we found that only $24 \%$ of the total subjects were having the habit of alcoholism, smoking, or both and this may not be the only risk factor in causing high-risk diseases in the study area.

\subsection{HAM characteristics:}

Characteristics of HAM's according to their formulation type, The number of prescriptions that are prescribed in generic and brand name, and the number of HAM's per prescription are represented in table 2.

Table 2: HAM characteristics and their numeral:

\begin{tabular}{|l|c|c|}
\hline \multicolumn{1}{|c|}{ HAM Characteristics } & $\begin{array}{c}\text { Number of encounters } \\
\mathbf{N}=\mathbf{4 2 0}\end{array}$ \\
\hline Oral & 87 & 20.7 \\
Parenteral & 333 & 79.2 \\
\hline Brand & 190 & 45.24 \\
Generic & 230 & 54.76 \\
\hline Drugs per prescription & & \\
Single HAM & 217 & 59.84 \\
Two HAMs & 93 & 25.69 \\
Three HAMs & 37 & 10.22 \\
Four HAMs & 12 & 3.31 \\
Five HAMs & 01 & 0.28 \\
Six HAMs & 02 & 0.55 \\
\hline
\end{tabular}

In 420 encounters, Oral and parenteral (Subcutaneous and Intravenous) formulations were used. Our data indicate that the majority of prescriptions contained parenteral preparations; this is obvious that intensive care admissions are generally required immediate management/action. In support of our data, the results of Anitta Thomas, et. al ${ }^{11}$ show that the most frequent route of administration of HAM is parenteral (79.2\%) followed by oral route $(20.7 \%)$. The majority of ICU studies document that the parenteral route is the most frequent route of administration.

Generally, drug names in the prescription should be in their generic/active ingredient name than their brand names to avoid duplications of drug class and therapeutic class. Most of our study drugs are prescribed in Generic names. Only 2 drugs are prescribed in Brand name. i.e., Insulin as ACTRAPID AND MIXTARD whereas Enoxaparin as BIOENOX. In our study site, we found a majority (54.7\%) of the drugs were prescribed in their generic/active ingredient name, which indicates the appropriate drug utilization.

The number of HAMs per prescription is an indicator of the severity of the high-risk diseases. A total of 420 HAM containing prescriptions were observed with 7 HAMs in 362 cases with an average of $1.62( \pm 0.916)$ HAMs per prescription. We found that majority were received single ISSN: 2250-1177
HAM $(60 \%)$ and the most commonly prescribed HAM is Insulin i.e. in 125 (34.5\%) prescriptions, which indicates the majority were suffered from uncontrolled hyperglycemia. The most commonly prescribed combination of HAMs was found to be Digoxin and Enoxaparin.

\subsection{Allocation of HAMs concerning their indications, ATC/DDD, and Cost:}

\subsubsection{ATC/DDD:}

All the study drugs were classified as per the standard guidelines of the ATC (Anatomical Therapeutic Chemical) classification system along with their Defined Daily Doses (DDD). The main purpose of the ATC/DDD system is to present drug utilization statistics that improves drug usage where it has been demonstrated to be suitable for national and international comparisons, for the evaluation of long term patterns in drug use, to assess the impact of certain events on drug use, and for providing denominator data in investigations of drug safety.

The defined daily dose is a standard dose calculated by the WHO after considering the dosing habits of different health care setups. It may be useful for comparing the dose 
prescribed with standard DDD to know the differences in the prescribing habits.

\subsubsection{Indications and ICD Codes:}

As only 7 high alert medications met the sample size criteria which accounts for 420 prescriptions in 362 cases, the detailed description about their ATC/DDD, indications, ICD(International Classification of Diseases) code, and cost details were represented in table 3 .

\subsubsection{Atropine:}

Atropine was prescribed in 42 prescriptions for 19 types of indications. Out of 42 prescriptions, 17 were prescribed majorly in cardiovascular conditions with or without comorbidities followed by poisoning conditions. Murat Sungur et al ${ }^{12}$ study has shown that the OP- Poisoning cases were prescribed with intravenous atropine and oximes commonly.

The utilization of the atropine in our study site is not according to the guidelines, as the average daily dose was 1 time more than the DDD and we have found 5 DRPs i.e. overdose induced ADRs like Psychosis (3) and Tachycardia (2). And in some cases, the drug administrator has not followed the prescription i.e. they are not writing the complete dose given to the patient as and when.

\subsubsection{Digoxin:}

Digoxin was prescribed in 44 prescriptions for 14 indications, which are cardiovascular problems with or without comorbidities. CHF(Congestive Heart failure) is a common indication. In parallel to our results, Christopher et. al ${ }^{13}$ also concluded that Digoxin was the cornerstone of therapy for patients with chronic heart failure. The average prescribed digoxin dose is as per DDD and we didn't found any harmful issues with digoxin. So, We found that digoxin use is appropriate as per guidelines in our study site.

\subsubsection{Enoxaparin:}

Enoxaparin was prescribed in 65 prescriptions for 18 types of indications. Out of 65 prescriptions, the majority of prescriptions (29) were for STEMI(ST-Segment elevated Myocardial Infarction), followed by CAD(Coronary Artery disease) i.e.,15. Similar to our results Andrea Rubboliet. al.,14 study had also reported that Enoxaparin is the most commonly prescribed in STEMI in conjunction with thrombolysis.

Though the average prescribed enoxaparin dose was not according to the guidelines i.e., higher than the defined daily dose, we did not found any negative issues in the subjects. The reason for this discrepancy is the unavailability of the exact strength.

\subsubsection{Glimepiride:}

Glimepiride was prescribed in 43 prescriptions for 3 types of indications. Out of 43 prescriptions, the majority were prescribed for diabetes mellitus with hypertension. The study by Massi Benedetti et.al.,15 states that glimepiride is an effective and well-tolerated once-daily antidiabetic drug for the management of type 2 diabetes.

We found that the average prescribed dose of glimepiride was appropriate as per the DDD. We did not found any harmful issues related to glimepiride use. Only one ADR was identified that is managed with medications and then reported to IPC PvPI.

\subsubsection{Insulin:}

Insulin was prescribed in 125 prescriptions for 9 types of indications. Out of125 prescriptions, we found that DM with HTN was a common indication treated with this drug after DM alone. The study results of Sanne G swinnen et. al ${ }^{\mathbf{1 6}}$, states that insulin had improved treatment satisfaction and quality-of-life for type 2 diabetic patients.

Though the average prescribed daily dose of insulin is as per the DDD, the dose calculation method being followed in our study site is not common for all the prescriptions, as some prescribers fix the dose according to the GRBS values while others follow the sliding scale method, but there is no display of sliding scale at the study site. We also found ADRs related to its use which can be managed with medications and reported to IPC PVPI.

\subsubsection{Midazolam:}

In our study site, Midazolam was prescribed in 60 prescriptions for 12 types of indications. Of them, 50\% were prescribed for Epilepsy/seizure disorders. The study results ofRob smith et. al17, specified that Midazolam was widely used as an off-label indication for Seizures, and the first-line treatment for status-epilepticus in children. But in our study, Midazolam was commonly prescribed for Epilepsy/seizure. We found that the average prescribed dose of midazolam was appropriate as per the DDD.

\subsubsection{Noradrenaline:}

In our study site, Noradrenaline was prescribed in 41 prescriptions for 21 types of indications. Of 41 prescriptions, 12 prescribed for cardiac disorders with or without comorbidities, followed by CVA and sepsis. Similar to our study, A study by Hamzaouiet. al18, states that nor-adrenaline is the first-line agent recommended during septic shock to correct hypotension.

The average prescribing dose of noradrenaline is as per the defined daily dose. As per the guidelines, nor-adrenaline should be diluted in $5 \% \mathrm{D}$, but we found in 11 cases the dilution of nor-adrenaline was done with NS, Which is incompatible, this may be due to lack of awareness regarding the dilution technique of noradrenaline. 
Table 3: Allocation of HAM's concerning their indications, ATC/DDD, and cost:

\begin{tabular}{|c|c|c|c|c|}
\hline Drug Name & ATC Code & Indication (ICD Code) & DDD & $\begin{array}{c}\text { Total } \\
\text { Cost(INR) }\end{array}$ \\
\hline Atropine & A03BA01 & $\begin{array}{l}\text { OP Poisoning (T60.0X1A), Unknown compound poisoning(T44.901), } \\
\text { Vasmol poisoning (T49.93XD), } \\
\text { CVA (I63.013), CVA with HTN (I63.013, I15.2), } \\
\text { Breast cancer With Lymphoedema (C79.81), CAD ( I25.10), CAD with } \\
\text { AV block (I25.10, I44.30), CAD with STEMI (I25.10), T2DM with Atrial } \\
\text { fibrillation (E11.618, I48.91), T2DM with MI (E11.618, I21.9), CHF } \\
\text { with IHD (I50.40), CAD with CHF (I50.9), } \\
\text { T2DM with septic shock (E11.618), MI (I21.9), Anemia with pleural } \\
\text { effusion (J91.8), DCLD (K70.9), Respiratory failure (J96.2), Angina } \\
\text { (I20.0), Cardio-respiratory arrest (R09.2) }\end{array}$ & $1.5 \mathrm{mg}$ & 112.94 \\
\hline Digoxin & C01AA05 & $\begin{array}{l}\text { CHF (I50.40), Atrial Fibrillation (I48.91), Cardiomyopathies (G72.81), } \\
\text { CHF With CAD (I50.40, I25.10) CAD (I25.10), Angina (I20.0), CVA } \\
\text { (I63.013), } \\
\text { CKD(N18.19), CHF with CKD (I50.40, N18.19), CHF with } \\
\text { Bronchiecstasis (I50.40, J47.1), HTN with Hyper Albuminemia (I15.2), } \\
\text { LVF/LVD (I50.1), MI With Seizures (I21.9), Cardiogenic Shock (R57.0) }\end{array}$ & $0.25 \mathrm{mg}$ & 43.73 \\
\hline Enoxaparin & B01AB05 & $\begin{array}{l}\text { STEMI (I21.21), NSTEMI (I22.2), LBBB, MI (I21.9), CAD with LVD } \\
\text { (I25.10, I50.1), CAD with HTN (I25.10, I15.2), CAD(I25.10), HTN with } \\
\text { ischemic stroke (I15.2, Z86.73), Venous Thrombosis (I82.211), } \\
\text { Pulmonary Embolism (I26.99), Atrial fibrillation (I48.91), CAD with AF } \\
\text { (125.10, I48.91), CHF with AF (I48.91, I50.40), CHF with T2DM } \\
\text { (I50.40, E11.618), } \\
\text { CHF with anemia (I50.40), AV conduction block (I44.30), Angina } \\
\text { (I20.0), Degenerative valvular disease (I27.9) }\end{array}$ & $40 \mathrm{mg}$ & 15753.88 \\
\hline Glimepiride & A10BB12 & $\begin{array}{l}\text { DM (E11.618), DM with HTN (E11.618, I15.2), DM with Cardiac } \\
\text { Disorder (E11.618, I 25.10) }\end{array}$ & $2 \mathrm{mg}$ & 117.04 \\
\hline Insulin & A10AD05 & $\begin{array}{l}\text { T2 Diabetes Mellitus (E11.618), Diabetes Mellitus With Hypertension } \\
\text { (E11.618, I15.2), Type 1diabetes Mellitus (E10.65), DM With CKD } \\
\text { (E11.618, N18.9), DM With Thyroid Disorders (E11.618, E07.9), DM } \\
\text { With CAD (E11.618, I25.10), DM With CVA (E11.618, I63.013), } \\
\text { DM With Respiratory Disorders (E11.618, J98.9), } \\
\text { DM With Seizures (E11.618, G40.A19) }\end{array}$ & $40 \mathrm{U}$ & 5002.7 \\
\hline Midazolam & N05CD08 & $\begin{array}{l}\text { Epilepsy /seizure disorder (G40.41), Seizures with CVA } \\
\text { (I63.013,G40.90), Unknown compound Poisoning (T43.64), Seizures } \\
\text { with PTB (G40.41, A15.0), absence seizure (G40.A19), seizure with } \\
\text { alcohol Dependence (G40.90,F10.229), status epilepticus } \\
\text { (G40.821),Generalized tonic-clonic Seizures (G40.309), seizures with } \\
\text { aspiration pneumonia (G40.A19 089.01), Burns (M61.30), altered } \\
\text { sensorium (R41.82), seizures with metabolic Disorders(E88.9) }\end{array}$ & $15 \mathrm{mg}$ & 970.26 \\
\hline $\begin{array}{c}\text { Noradrenali } \\
\text { ne }\end{array}$ & C01CA03 & $\begin{array}{l}\text { CAD (I25.10), CAD With T2DM (I25.10, E11.618), CVA (I63.013), CVA } \\
\text { with thrombocytopenia (I63.016), Hypovolemic shock (R57.1), } \\
\text { Cardiogenic shock with AKI (R57.0, S37.0), CAD with CHF (I25.10, } \\
\text { I50.9), Sepsis (A41.9), Sepsis with T1 DM (A41.9, E10.65), Sepsis with } \\
\text { portal HTN (A41.9, K76.6), Cardiomyopathy (I42.0), DCLD with portal } \\
\text { hypertension (K76.9), Anemia with pleural effusion (J91.8), } \\
\text { Cardiorespiratory arrest (R09.2), Pneumonia (J18.9), Aspiration } \\
\text { pneumonia (089.01), Hypoglycemia attack (E16.2), Aspiration } \\
\text { pneumonia with hypoglycemia (O89.01, E16.2), Chronic kidney injury } \\
\text { (N18.9), Breast cancer (C79.81), GTCS (G40.89) }\end{array}$ & $6 \mathrm{mg}$ & 1075.13 \\
\hline
\end{tabular}

\subsubsection{Cost of study drugs:}

One of the objectives of the DUE process is to estimate the cost of drug therapy and promote better economic treatment. Based on our study results, the Cost/amount spent on 7 HAMs was estimated and found that INR $23,075.75$ with an average INR 63.75 /patient was spent by the government for 362 patients during the study period. The individual cost of all the study drugs was calculated and which of total cost spent, enoxaparin (65) was listed to be the costliest drug among 7 drugs and it occupied $68.26 \%$ of the total cost of seven drugs, and digoxin was listed to be the low-cost drug and it occupied $0.41 \%$ of the total cost of seven drugs.
As this study center is a government health care center, there is no burden for the patients and no need to pay from their pocket. We have not analyzed the cost spent and outcome of the treatment, with this data we cannot conclude the right cost as we have not compared it with any other costs.

\subsection{Drug-Related Problems:}

A drug-related problem is anything that is involving drug therapy that interferes with the desired outcome for a patient. The 8 types of DRPs are Untreated indication, Improper drug selection, Low dose, overdose, failure to receive drugs, ADRs, Interactions, and drug use without indication ${ }^{19}$. 
Out of 8 types of Drug-Related Problems, we observed overdose of Atropine in 5 patients, and 09 ADRs were developed by the patients during the study period of which 5 were due to the overdose of Atropine. Of 133 drug interactions, 2 were actual DDI's, and 131 were potential DDI's. The detailed description of DRPs is represented in table 4 .
We have done intervention to the DRPs identified for better patient response. The DRP's we identified were derived from the standard source of information ${ }^{20}$. The study results by SachinRavalet.al ${ }^{3}$, also states that the primary focus should be on preventing the errors of HAMs with the greatest potential to improve patient safety.

Table 4: Drug-related problems

\begin{tabular}{|c|c|c|c|c|c|c|c|c|c|}
\hline \multirow[b]{2}{*}{ Drug name } & \multicolumn{8}{|c|}{ Drug-Related Problems } & \multirow[t]{2}{*}{ TOTAL } \\
\hline & $\begin{array}{l}\text { Untreated } \\
\text { indication }\end{array}$ & $\begin{array}{l}\text { Improper } \\
\text { drug } \\
\text { selection }\end{array}$ & $\begin{array}{l}\text { Subthera } \\
\text { peutic } \\
\text { dose }\end{array}$ & $\begin{array}{l}\text { Overd } \\
\text { ose }\end{array}$ & $\begin{array}{l}\text { Failure } \\
\text { to } \\
\text { receive } \\
\text { drugs }\end{array}$ & $\begin{array}{l}\text { ADR } \\
\text { 's }\end{array}$ & $\begin{array}{l}\text { Drug } \\
\text { intera } \\
\text { ctions }\end{array}$ & $\begin{array}{l}\text { Drug use } \\
\text { without } \\
\text { indication }\end{array}$ & \\
\hline Atropine & - & - & - & 05 & - & 05 & 08 & - & 18 \\
\hline Digoxin & - & - & - & - & - & - & 19 & - & 19 \\
\hline Enoxaparin & - & - & - & - & - & - & 31 & - & 31 \\
\hline Glimepiride & - & - & - & - & - & 01 & 06 & - & 07 \\
\hline Insulin & - & - & - & - & - & 02 & 24 & - & 26 \\
\hline Midazolam & - & - & - & - & - & 01 & 35 & - & 36 \\
\hline Noradrenaline & - & - & - & - & - & - & 02 & - & 02 \\
\hline $\begin{array}{l}\text { Calcium } \\
\text { gluconate }\end{array}$ & - & - & - & - & - & - & 01 & - & 01 \\
\hline Labetalol & - & - & - & - & - & - & 03 & - & 03 \\
\hline Amiodarone & - & - & - & - & - & - & 02 & - & 02 \\
\hline Meropenem & - & - & - & - & - & - & 01 & - & 01 \\
\hline Linezolid & - & - & - & - & - & - & 01 & - & 01 \\
\hline Total & - & - & - & 05 & - & 09 & 133 & - & 147 \\
\hline
\end{tabular}

\subsubsection{ADR's}

Among the 9 ADRs, 7 were common and 2 are lifethreatening reactions. All the ADRs were reported to the IPC PvPI after thorough analysis and MedDRA (Medical Dictionary for Regulatory Authority) code was given as represented in the table below.
We have represented the MedDRA code for the observed adverse drug reactions which is a standardized International medical terminology used to convert adverse event information into terminology that can be readily identified, retrieved, and analyzed.

Table 5: Adverse Drug Reactions and its MedDRA code

\begin{tabular}{|c|c|c|c|}
\hline S.No. & Drug & Reaction & MedDRA code \\
\hline 1. & Insulin & Hypoglycemia (2) & 10022485 \\
\hline 2. & Atropine & Psychosis (2) & 10037234 \\
\hline 3. & Atropine & Tachycardia (3) & 10043071 \\
\hline 4. & Glimepiride & Bleeding Gums (1) & 10018771 \\
\hline 5. & Midazolam & Shortness of Breath (1) & 10041237 \\
\hline
\end{tabular}




\subsubsection{Drug-Drug Interactions:}

DDI is one of the Drug-related problems which alter the drug effects and outcome. A total of 133 Drug-drug Interactions were found. Of them, 2 were actual and 131 were potential. The study results by Aline Teotonio Rodrigues et al $^{21}$ also states that the clear majority of ICU prescriptions had at least one potential DDI, and the most prevalent ones were classified as moderate. Admitting that high potential for Drug-Drug Interactions in the ICU represents an important step toward improving patient safety and best therapy results.

Table 6: Drug-Drug Interactions:

\begin{tabular}{|c|c|c|c|c|}
\hline S.No: & \multicolumn{3}{|c|}{ Drug-drug interactions } & TOTAL \\
\hline & \multirow[t]{2}{*}{ Actual } & \multicolumn{2}{|c|}{ Potential } & \\
\hline & & Serious & Moderate & \\
\hline 1. & 02 & 24 & 107 & 133 \\
\hline
\end{tabular}

Actual drug-drug interactions:

The 2 observed actual DDI's (2) were with Meropenem and linezolid. The consequences of the actual DDIs were observed in patients clinically, as it is not possible to analyze through the laboratory at our study site, so we have confirmed clinically and intervention was done for those interactions.

Potential drug-drug interactions:

Of all the 133 DDI's, 131 DDI's were potential (not clinically observed in subjects). Among them, Serious DDIs were observed with 4 drug combinations and these combinations were prescribed in 24 prescriptions. Serious interactions are those interactions that are required to change the drug or avoid the use together. The most common DDI observed in this category is Digoxin along with Pantoprazole (i.e., $71 \%$ ). Fortunately, the consequences of these interactions are not observed in our study subjects.

Of 131 potential DDIs, Moderate interactions were observed with 24 drug combinations and these combinations were prescribed in 107 prescriptions. Moderate interactions are those interactions that are required to monitor the consequences closely.

Among the 362 subjects, we observed that $42 \%$ of the subjects were discharged after recovery. Around $20 \%$ of patients died during the therapy in the ICCU and MICU. We found that one patient who was on ventilation was suspected to die due to ADR i.e. Midazolam induced breathlessness. A study result by Maharani et. al[22], states that More than half of the patients admitted in ICU were discharged with improvement in the condition for which they were admitted.

\subsection{Drug Duplication:}

We observed 2 Drug duplications with our study drugs among all the prescriptions (Insulin prescribed as ACTRAPID and MIXTARD, which were prescribed in 17 prescriptions). We also observed Therapeutic duplication with one class of drugs i.e., Insulin and Glimepiride, which are prescribed in 14 prescriptions. Though there was drug duplication, we did not found any issues related to the duplication. As the blood glucose levels were not controlled in those patients, they have prescribed two hypoglycemic agents.

\section{CONCLUSION:}

Utilization of high alert medications is appropriate to the standards and criteria of the study in the majority of the prescriptions i.e appropriate ROA, almost all the HAMs are written in their active ingredient/generic names, and we found very few drug-related problems such as overdose induced ADRs. We have observed a one-off labeled indication for Midazolam and the remaining drugs were prescribed for their labeled indications. The prescribed dose of the study drugs is comparable to the WHO-DDD and appropriate to the patient's condition.

Though, the DUE of HAMs is appropriate still some issues that need to be addressed were as follows: The dose calculation method is not uniform by all the prescribers. The dilution technique being followed for noradrenaline is not as per the specifications and no information chart/dilution technique is displayed on the study site. We have observed the usage of the same strength of enoxaparin for both loading and maintenance doses. Drug administrators are not mentioning in the prescription the exact dose administered to the patient for Atropine. Maintenance of ward pharmacy is not up to the standards; there is no regular check for expiry drugs, deteriorated drugs, drug misplaces, and not following the labeling standards especially for SALA high alert drugs. Finally, we conclude that there is a need to establish a DUE committee lead by a clinical pharmacist to identify such issues in time and rectify them for the improvement of drug use especially in emergency departments like ICCU.

\section{FUNDING:}

The authors declare that no funding has been received from any source.

\section{ACKNOWLEDGEMENT:}

The authors of this article would like to acknowledge the HOD of pharmacy practice, PRRMCP, Medical Record Department, RIMS for their support.

\section{AUTHOR CONTRIBUTION:}

All the authors have an equal contribution.

\section{DECLARATION OF INTEREST:}

The authors of this article declare no conflict of interest.

\section{ABBREVIATIONS:}

DM: Diabetes Mellitus, HTN: Hypertension, GRBS: General Random Blood Sugar, IPC PvPI: Indian Pharmacopoeia commission Pharmacovigilance Programme of India, OP Poisoning: Organo Phosphorous compound poisoning, CVA: Cerebro Vascular Accident, AVblock: Artrio-ventricular block, STEMI: ST-segment elevated Myocardial infarction, NSTEMI: Non-ST segment elevated myocardial infarction, T2DM: Type 2 Diabetes Mellitus: MI: Myocardial Infarction, CHF: Congestive Heart Failure, IHD: Ischaemic heart disease, CAD: Coronary Artery disease, DCLD: Decompensated liver disease, CKD: Chronic kidney disease, LVD: Left ventricular 
dysfunction, LBBB: Left Bundle Branch Block, PTB: Pulmonary Tuberculosis, AKI: Acute kidney injury, GTCS: Generalized Tonic-clonic seizures.

\section{REFERENCES:}

[1] High risk medicines::SA Health [internet], [updated 2019July 25 cited sept 2019 05], https://www.sahealth.sa.gov.au/wps/wcm/connect/public+c ontent/sa+health+internet/clinical+resources/clinical+topics /medicines+and+drugs/high+risk

[2] Preventing high-alert medication errors in hospital patients [internet]2019[updated 2015 may 11;cite2019 oct 03].https://www.americannursetoday.com/preventing-highalert-medication-errors

[3] Saed H. Zyoud, Samar M. Khaled, Baraa M. Kawasmi, et al., Knowledge about the administration and regulation of high alert medications among nurses in Palestine: a cross-sectional study; BMC Nursing (2019) 18:11

[4] High-Alert Medications in Acute Care Settings[internet]2019[updated 2018 Aug 23].https://www.ismp.org/recommendations/high-alertmedications-acute-list.

[5] Ilse Truter; A Review of Drug Utilization Studies and Methodologies; Jordan Journal of Pharmaceutical Sciences, $2008,1(2)$.

[6] What are Drug Utilization Reviews (DUR), (internet),2009, Extracted from The Academy of Managed Care Pharmacy's Concepts in Managed Care Pharmacy.

[7] Shalini.S.Ravichandran. V, Mohanty. B.K et al., drug utilization studies; An overview, IJPSN, 3(1).2010 pp.803-811

[8] G. Parthasarathy, Karin NY fort -Hansen, Mila C Napata. A textbook of clinical pharmacy practice essential concepts and skills. $2^{\text {nd }}$ edition. 2012. Universities press publications. pp. 447-460.High-Alert Medications in Acute Care Settings[internet]2019[updated 2018 Aug 23].https://www.ismp.org/recommendations/high-alertmedications-acute-list.

[9] Manjula Devi et.al, a study on prescribing pattern of high alert medications in the medical intensive care unit; IOSR Journal of dental and medical sciences (IOSR-JDMS); December. 2018; 17(12);pp 23-26

[10] Mitchel Kim et.al, older adults and high-risk medications administration in the emergency department; Drug Health Patient Saf. 2017; 9; 105-112

[11] Anitta Thomas et.al, Drug utilization pattern in adult medical intensive care unit of a tertiary care hospital; Chrismed journal of health and research; 6(1), pp35-38

[12] Murat sungur et.al, intensive care management of organophosphate insecticide poisoning; Critical care 2001, 5; pp 211-215.

[13] Christopher et.al, R The Role of Digoxin in the Treatment of Heart Failure Circulation; Heart Failure. 2008;1;pp 206-207.

[14] Andrea Rubboli et.al, Utilizing Enoxaparin in the management of STEMI; Vascular Health and Risk Management 3(5); pp 691 700

[15] Massi Benedetti et.al, Glimepiride in type 2 diabetes mellitus; a review of the worldwide therapeutic experience; ClinTher. 2003 Mar;25(3); pp; 799-816.

[16] Sanne G swinnen et.al, Insulin Therapy for Type 2 Diabetes; Diabetes Care. 2009 Nov;32(Suppl 2); pp; 253-259.

[17] Rob smith et.al; Midazolam for status epileticus ;AustPrescr. 2017 feb ; 40(1)'pp 23-25

[18] Hamzaouiet. al; Norepinephrine in septic shock: when and how much; CurrOpinCrit Care. 2017 Aug;23(4):pp:342-347

[19] MEDICATION-RELATED ISSUES/Alzpossible [internet]2007[Dec 5],https://alzpossible.org/medicationrelated-issues/

[20] Joseph T.Dipiro: AHFS Drug handbook: second edition: Springhouse Lippincott Williams and Wilkins publications: pp - 167-169, 399 - 403, 459 - 462, 577 - 578, 651 - 652, 818 $821,889-890$.

[21] Aline Teotonio Rodrigues et al: Prevalence of potential drugdrug interactions in the intensive care unit of a Brazilian teaching hospital: Braz. J. Pharm. Sci.2017;53(1):e16109

[22] Maharani et.al, the Prescription pattern of patients admitted in the intensive care unit of a tertiary care hospital in Puducherry, India: a cross-sectional study; IJBCP; DEC 2017;6(12), 2822. 